\title{
Incidence and predictive factors for recurrent clear cell ovarian carcinoma: results from a single center in Thailand
}

\author{
Wikanda Hemman, MD, Athithan Rattanaburi, MD \\ Division of Gynecologic Oncology, Department of Obstetrics and Gynecology, Faculty of Medicine, Prince of Songkla University, Songkhla, Thailand
}

\section{Objective}

We aimed to study the incidence and predictive factors of recurrent clear cell ovarian carcinoma (CCC) and evaluate the oncological outcomes after recurrence.

\section{Methods}

This was a retrospective study of 134 CCC cases diagnosed between 2005 and 2020. Clinicopathological data and oncological outcomes were extracted and evaluated. Patients with co-malignancy, mixed pathological type, or incomplete data were excluded. Descriptive statistics, univariate and multivariable analyses, and Kaplan-Meier survival probability estimates were completed. A proportional hazards model was used to assess the association between the prognostic factors with progression-free survival (PFS), overall survival (OS), and post-recurrence survival.

\section{Results}

A total of 134 patients with CCC were enrolled. The incidence of recurrent CCC was $33.6 \%$ (45/134). The median PFS was 12.8 months (95\% confidence interval $[\mathrm{Cl}], 9.66-18.9)$ in the recurrence group and 3.3 months $(95 \% \mathrm{Cl}, 1.15-4.4)$ in the refractory group. Residual tumor from surgical outcome, ascites cytology, and lymphovascular space invasion (LVSI) were independent prognostic factors for PFS. The significant variables were residual tumor (sub-optimal surgery vs. optimal surgery) (hazard ratio $[\mathrm{HR}], 2.68 ; 95 \% \mathrm{Cl}, 1.48-4.87 ; P=0.002)$, ascites cytology (positive vs. negative) (HR, 2.8; $95 \% \mathrm{Cl}, 1.58-4.98 ; P=0.002)$, and LVSI (positive vs. negative) (HR, 2.14; $95 \% \mathrm{Cl}, 1.18-3.86 ; P=0.04)$. The median postrecurrence survival was 13.96 months $(95 \% \mathrm{Cl}, 10.61-26.2)$ in the recurrence group.

\section{Conclusion}

CCC has a high rate of recurrence. Sub-optimal surgery, positive ascites cytology, and LVSI indicated a worse prognosis for PFS. Optimal cytoreductive surgery is an important part of primary treatment to improve survival in patients with CCC.

Keywords: Adenocarcinoma clear cell; Ovarian cancer; Prognosis; Incidence; Recurrence

\section{Introduction}

Ovarian cancer is the third most common gynecological cancer worldwide [1]. The most common type is serous carcinoma, which accounts for $75-80 \%$ of all epithelial ovarian cancers [2]. Clear cell ovarian carcinoma (CCC) is a rare type of ovarian cancer. Among ethnic groups, CCC has a different prevalence. The prevalence of ovarian CCC was $5 \%$ in the entire female population, whereas its prevalence in the Asian population has increased to $13-25 \%[3,4]$.

Patients with CCC usually present with early stage disease
Received: 2021.10.10. Revised: 2021.12.26. Accepted: 2022.01.05. Corresponding author: Athithan Rattanaburi, MD

Division of Gynecologic Oncology, Department of Obstetrics and Gynecology, Faculty of Medicine, Prince of Songkla University, 15 Karnjanavanich Rd., Hat Yai, Songkhla 90110, Thailand E-mail: r_athithan123@hotmail.com https://orcid.org/0000-0002-9423-5569

Articles published in Obstet Gynecol Sci are open-access, distributed under the terms of the Creative Commons Attribution Non-Commercial License (http://creativecommons. org/licenses/by-nc/3.0/) which permits unrestricted non-commercial use, distribution, and reproduction in any medium, provided the original work is properly cited.

Copyright (C) 2022 Korean Society of Obstetrics and Gynecology 


\section{Obstetrics \& Gynecology Science}

Wikanda Hemman, et al. Recurrent clear cell ovarian carcinoma

and are younger than those with serous epithelial ovarian carcinoma [5]. Even though patients present with early stage disease, patients with CCC still have a high rate of recurrence [6]. Currently, the treatment of CCC is based on evidence-based studies of epithelial ovarian carcinoma, which is mainly composed of serous ovarian carcinoma and a small percentage of CCC patients. The standard treatment for ovarian carcinoma is surgical staging and platinum-based chemotherapy, which depends on the stage of the disease $[7,8]$. Current guidelines for the management of epithelial ovarian carcinoma do not distinguish between different histological or molecular subtypes. The response rate of CCC to chemotherapy was lower in the primary and recurrent treatment settings. A previous study reported that $<10 \%$ of CCC patients were platinum-sensitive, and $1 \%$ of patients had platinum-resistant disease [9]. Therefore, it is important to identify the prognostic factors of CCC to establish guidelines for treatment and prognosis evaluation.

Due to the high prevalence of CCC in the Asian population, this study aimed to evaluate the incidence of recurrent CCC, the predictive factors of recurrent disease, and the oncological outcomes after recurrence of the disease.

\section{Materials and methods}

A retrospective study was conducted in 134 patients diagnosed with CCC and treated with primary cytoreductive surgery or neoadjuvant chemotherapy followed by interval debulking surgery in the Department of Obstetrics and Gynecology of Songklanagarind Hospital between January 2005 and March 2020. Patients who had co-malignancies, mixed pathological type, received previous chemotherapy or radiotherapy, had incomplete medical records, or were lost to follow-up were excluded. The study was approved by the Research Ethics Committee of the Faculty of Medicine, Prince of Songkla University (REC 63-167-12-4).

The following variables of all patients were reviewed and collected: age at diagnosis, preoperative level of serum cancer antigen 125 (CA 125), stage at diagnosis based on the 2014 International Federation of Gynecology and Obstetrics (FIGO) staging system; primary treatment, tumor size, residual tumor after primary surgery, ascites cytology; lymphovascular space invasion (LVSI), adjuvant treatment, chemotherapy regimen, site of recurrent disease, current disease status, and date of death or last follow-up. The term "suboptimal surgery" was defined by the presence of a residual tumor from surgery that was greater than $1 \mathrm{~cm}$; an "optimal surgery" was defined by the lack of residual tumors or the presence of a residual tumor from surgery that was smaller than $1 \mathrm{~cm}$. Recurrent disease was defined by recurrence after complete remission from the primary treatment; it was identified via physical examinations, tumor markers, radiological imaging, and/or histological diagnoses. The term "refractory" in this study was used to define a partial response, stable disease, or progression of the disease after primary treatment. Progression-free survival (PFS) was defined as the period from the time of diagnosis to the time of recurrence or progression, the last follow-up, or death from any cause. Overall survival (OS) was defined as the period from the time of diagnosis to the time of last follow-up or death from any cause. Post-recurrence survival was defined as the period from the time of diagnosis of first recurrence or progression to the last follow-up or death from any cause.

The data were processed using R version 3.4.3 (R Foundation for Statistical Computing). Kaplan-Meier analysis was used to determine PFS, OS, and post-recurrence survival. Multivariable analysis was performed using the Cox proportional hazards model to evaluate the independent factors affecting survival. Hazard ratios (HRs) and 95\% confidence intervals (Cls) were also calculated. Statistical significance was set at $P<0.05$.

\section{Results}

A total of 134 CCC cases were included and analyzed in this study. The population was divided into three groups: 64 cases (47.8\%) with remission of disease, 45 cases (33.6\%) with recurrent disease, and 25 cases (18.7\%) with refractory disease. In this study, the overall incidence of recurrent CCC was $33.6 \%$ (45/134). Patient characteristics at the time of initial diagnosis are shown in Table 1. The mean age of the entire population was 51.5 (standard deviation [SD], 8.6) years. The mean (interquartile range, IQR) initial level of CA 125 was $116 \mathrm{IU} / \mathrm{mL}$ (39.2-384.8). Of all patients, 32/134 (23.9\%) of CCC cases in this study had normal pretreatment CA 125 levels ( $<35 \mathrm{IU} / \mathrm{mL}$ ). The vast majority of 96 patients $(71.6 \%)$ had early stage disease (stage I to II), and 38 patients (28.4\%) had advanced stage disease (stage III to IV). Most patients 


\section{Obstetrics \& Gynecology Science}

Vol. 65, No. 2, 2022

Table 1. Baseline patient characteristics

\begin{tabular}{|c|c|c|c|c|c|}
\hline Clinicopathological feature & Remission & Recurrence & Refractory & Total & $P$-value \\
\hline Total & $64(47.8)$ & $45(33.6)$ & $25(18.6)$ & $134(100.0)$ & \\
\hline Age at diagnosis & $52.5 \pm 9.1$ & $50.8 \pm 7.9$ & $50 \pm 8.5$ & $51.5 \pm 8.6$ & 0.372 \\
\hline Age (yr) & & & & & 0.495 \\
\hline$<50$ & $23(35.9)$ & $20(44.4)$ & $12(48.0)$ & $55(41.0)$ & \\
\hline$\geq 50$ & $41(64.1)$ & $25(55.6)$ & $13(52.0)$ & $79(59.0)$ & \\
\hline Initial CA 125 & $72.5(29.0-212.8)$ & $157(41-542)$ & $384(102-871)$ & $116(39.2-384.8)$ & 0.002 \\
\hline CA 125 level mean (IU/mL) & & & & & 0.066 \\
\hline$\leq 35$ & $20(31.3)$ & $10(22.2)$ & $2(8.0)$ & $32(23.9)$ & \\
\hline$>35$ & $44(68.7)$ & $35(77.8)$ & $23(92.0)$ & $102(76.1)$ & \\
\hline FIGO stage & & & & & $<0.001$ \\
\hline । & $28(43.8)$ & $11(24.4)$ & $7(28.0)$ & $46(34.4)$ & \\
\hline$\|$ & $28(43.8)$ & $17(37.8)$ & $5(20.0)$ & $50(37.3)$ & \\
\hline III & $6(9.3)$ & $17(37.8)$ & $12(48.0)$ & $35(26.1)$ & \\
\hline IV & $2(3.1)$ & $0(0.0)$ & $1(4.0)$ & $3(2.2)$ & \\
\hline FIGO stage & & & & & $<0.001$ \\
\hline Early & $56(87.5)$ & $28(62.2)$ & $12(48.0)$ & $96(71.6)$ & \\
\hline Advanced & $8(12.5)$ & $17(37.8)$ & $13(52.0)$ & $38(28.4)$ & \\
\hline Primary treatment & & & & & 0.710 \\
\hline Primary surgery & $61(95.3)$ & $43(95.6)$ & $25(100.0)$ & $129(96.3)$ & \\
\hline NACT & $3(4.7)$ & $2(4.4)$ & $0(0.0)$ & $5(3.7)$ & \\
\hline Surgical outcome & & & & & $<0.001$ \\
\hline Optimal surgery & $62(96.9)$ & $38(84.4)$ & $14(56.0)$ & $114(85.1)$ & \\
\hline Sub-optimal surgery & $2(3.1)$ & $7(15.6)$ & $11(44.0)$ & $20(14.9)$ & \\
\hline Tumor size $(\mathrm{cm})$ & $12(10,16)$ & $13(10,17)$ & $12(10,14)$ & $12(10,16)$ & 0.570 \\
\hline Ascites cytology & & & & & $<0.001$ \\
\hline Negative & $41(64.1)$ & $18(40.0)$ & $7(28.0)$ & $66(49.3)$ & \\
\hline Positive & $6(9.3)$ & $20(44.4)$ & $11(44.0)$ & $37(27.6)$ & \\
\hline No data & $17(26.6)$ & $7(15.6)$ & $7(28.0)$ & $31(23.1)$ & \\
\hline LVSI & & & & & 0.057 \\
\hline Negative & $33(51.6)$ & $19(42.2)$ & $10(40.0)$ & $62(46.3)$ & \\
\hline Positive & $5(7.8)$ & $11(24.4)$ & $8(32.0)$ & $24(17.9)$ & \\
\hline No data & $26(40.7)$ & $15(33.3)$ & $7(28.0)$ & $48(35.8)$ & \\
\hline Lymph node involvement & & & & & $<0.001$ \\
\hline Positive & $0(0.0)$ & $8(17.8)$ & $3(12.0)$ & $11(8.2)$ & \\
\hline Negative & $43(67.2)$ & $37(82.2)$ & $12(48.0)$ & $92(68.7)$ & \\
\hline No data & $21(32.8)$ & $0(0.0)$ & $10(32.3)$ & $31(23.1)$ & \\
\hline Adjuvant chemotherapy & & & & & 1.000 \\
\hline No & $1(1.6)$ & $0(0.0)$ & $0(0.0)$ & $1(0.7)$ & \\
\hline Yes & $63(98.4)$ & $45(100)$ & $25(100)$ & $133(99.3)$ & \\
\hline Chemotherapy & & & & & 0.526 \\
\hline No data & $0(0.0)$ & $0(0.0)$ & $0(0.0)$ & $1(0.0)$ & \\
\hline Platinum-based & $63(100.0)$ & $45(100.0)$ & $25(100.0)$ & $133(100.0)$ & \\
\hline
\end{tabular}

Values are presented as mean \pm standard deviation, median (interquartile range), or number (\%).

CA 125, cancer antigen 125; FIGO stage, International Federation of Gynecology and Obstetrics stage 2014; NACT, neoadjuvant chemotherapy; LVSI, lymphovascular space invasion. 


\section{Obstetrics \& Gynecology Science}

Wikanda Hemman, et al. Recurrent clear cell ovarian carcinoma

(96.3\%) were treated with primary cytoreductive surgery followed by platinum-based chemotherapy, and $85 \%$ of the

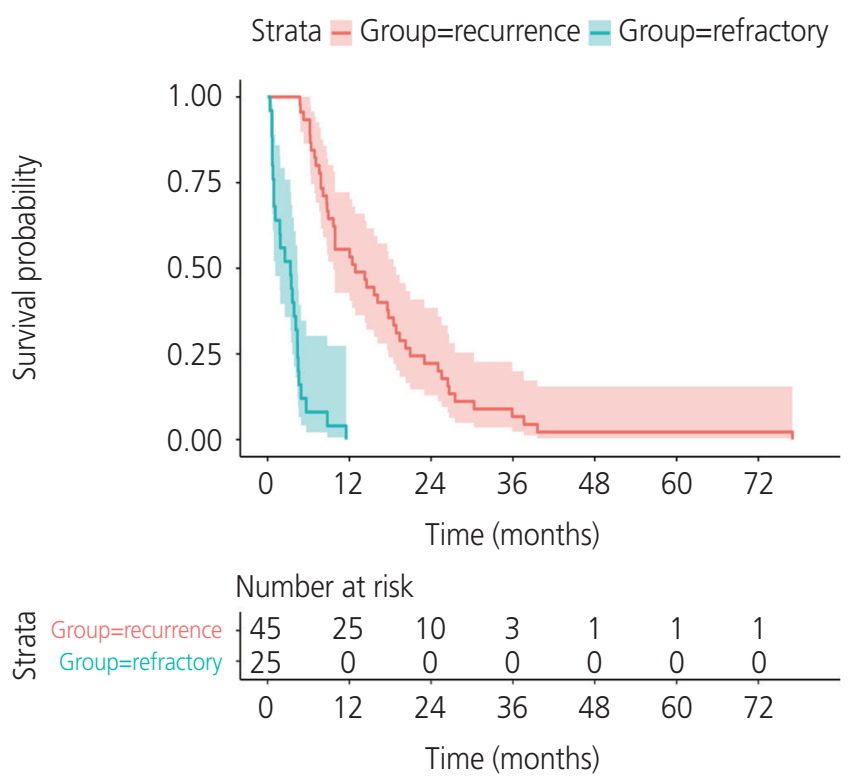

Fig. 1. Kaplan-Meier analysis of progression-free survival according to group. patients achieved an "optimal surgery". All patients presented with an average tumor size ranging from 10 to $16 \mathrm{~cm}$. Ascites cytology was positive in $27.6 \%$ of patients. LVSI was present in $17.9 \%$ of the patients. Of the entire study group, $11 / 134$ (8.2\%) had nodal involvement. Most patients (99.3\%) received adjuvant platinum-based chemotherapy. None of the patients received radiotherapy or bevacizumab as part of their primary treatment. Significant statistical differences were revealed between the three groups in terms of initial preoperative CA 125 level at the time of diagnosis, FIGO stage, ascites cytology, residual tumor from primary surgical outcome, and lymph node involvement. The median (IQR) CA 125 levels in the remission, recurrence, and refractory groups were $72.5 \mathrm{IU} / \mathrm{mL}$ (29-212.8), $157 \mathrm{IU} / \mathrm{mL}$ (41-542), and $384 \mathrm{IU} / \mathrm{mL}$ (102-871) ( $P=0.002)$. Advance-stage disease in the remission, recurrence, and refractory groups was found in $12.5 \%, 37.8 \%$, and $52 \%$ of the patients, respectively $(P<0.001)$. The patients with positive ascites cytology in the remission, recurrence, and refractory groups were 6/64 $(9.3 \%), 20 / 45(24.4 \%)$, and $11 / 25(44 \%)$, respectively $(P<0.001)$. The number (percentage) of patients with sub-

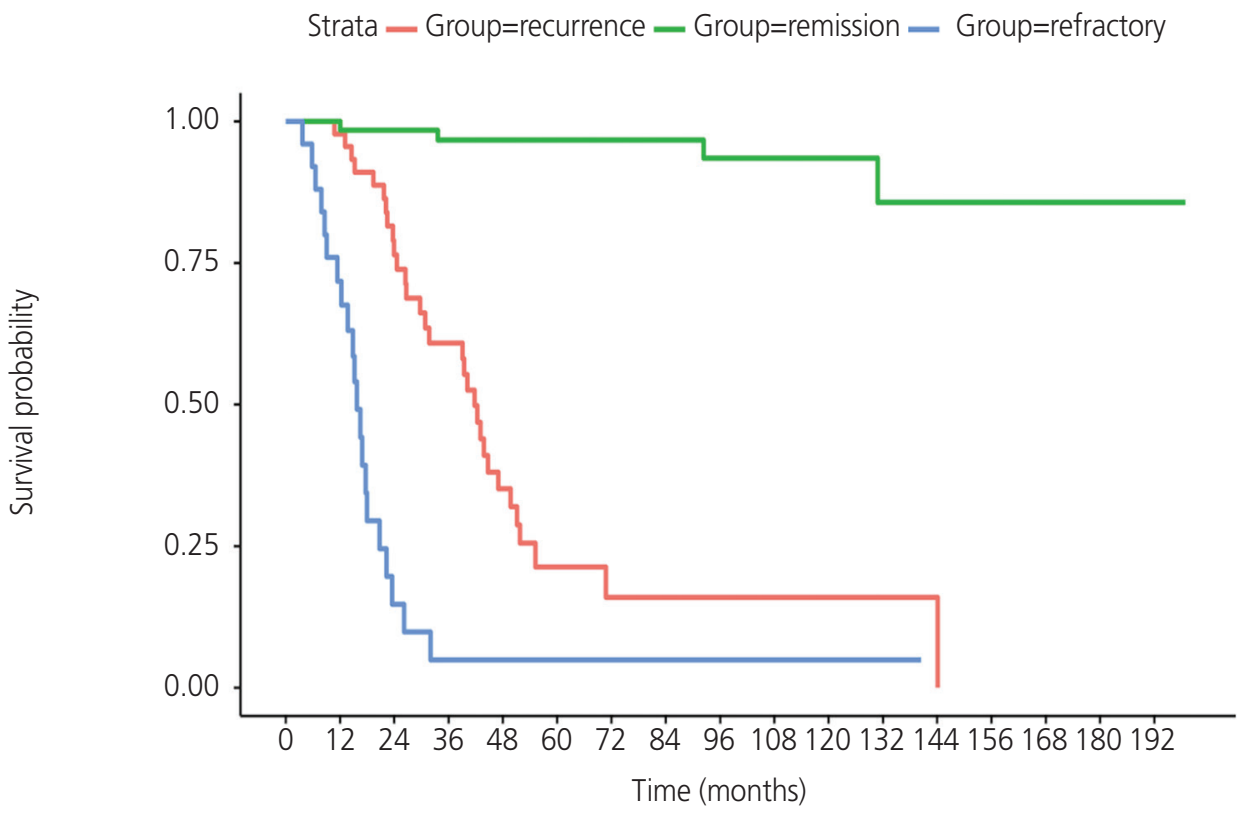

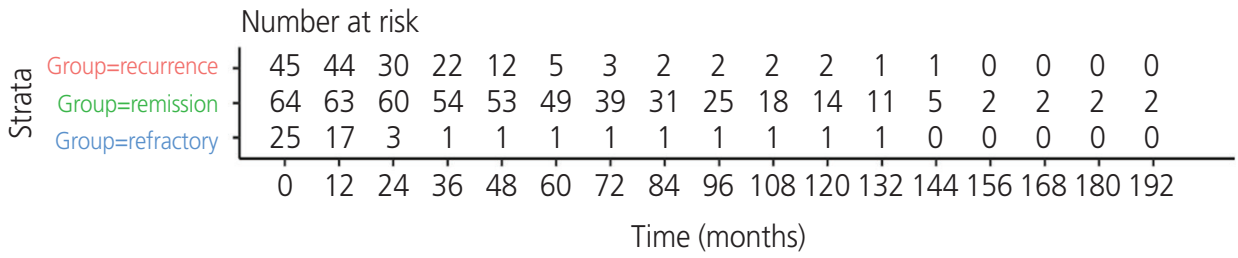

Fig. 2. Kaplan-Meier analysis of overall survival according to group. 


\section{Obstetrics \& Gynecology Science}

Vol. 65, No. 2, 2022

optimal surgery in the remission, recurrence, and refractory groups were $2 / 65(3.1 \%), 7 / 45(15.6 \%)$, and 11/25 (44\%), respectively $(P<0.001)$. The number (percentage) of patients with positive lymph node involvement in the remission, recurrence, and refractory groups were $0(0.0 \%), 8(17.8 \%)$, and $3(12.0 \%)$, respectively $(P<0.001)$.

The median follow-up time of the entire cohort was 40.5 months $(95 \% \mathrm{Cl}, 15.9-76.1)$. At the time of analysis, 56/134 $(41.8 \%)$ died of the disease, and the remaining $78 / 134$ $(58.2 \%)$ survived. In the group that survived, $60 / 78$ (76.92\%) had no evidence of disease and 18/78 (23.07\%) continued to live with the disease. Survival curves were estimated using the Kaplan-Meier method. The median PFS was 12.8 months $(95 \% \mathrm{Cl}, 9.66-18.9)$ for the recurrence group and 3.3 months $(95 \% \mathrm{Cl}, 1.15-4.4)$ for the refractory group (Fig. 1). The median OS values were as follows: not reached,
41.7 months $(95 \% \mathrm{Cl}, 31.7-51.1)$, and 15.7 months (95\% $\mathrm{Cl}, 13.7-22.3)$ for the remission, recurrence, and refractory groups, respectively (Fig. 2).

For stages I, II, and III, the median PFS values were 17.58 months ( $95 \% \mathrm{Cl}, 12.8$ to not applicable [NA]), 17.74 months (95\% Cl, 9.6-25.0), and 9.89 months $(95 \% \mathrm{Cl}, 7.82-16.1)$, respectively. The 1-year PFS rates for stages I, II, and III were $72.7 \%, 58.8 \%$, and $41.1 \%$, respectively. The 3 -year PFS rates for stages I, II, and III were $9.0 \%, 5.8 \%$, and $5.8 \%$, respectively. The OS rates at 1, 3, and 5 years were $94.0 \%$, $69.2 \%$, and $57.1 \%$, respectively, for the entire population. For the remission, recurrence, and refractory groups, the OS rates at 1 year were $100 \%, 97.8 \%$, and $71.8 \%$; at 3 years, they were $96.7 \%, 60.9 \%$, and $4.91 \%$, respectively, and at 5 years they were $96.7 \%, 21.3 \%$, and $4.91 \%$, respectively.

In the univariate analysis (Table 2), FIGO stage, surgical out-

Table 2. Univariate and multivariate analyses for factors associated with PFS

\begin{tabular}{|c|c|c|c|c|}
\hline \multirow{2}{*}{ Factor } & \multicolumn{2}{|c|}{ Univariate } & \multicolumn{2}{|c|}{ Multivariate } \\
\hline & HR (95\% Cl) & $P$-value & HR $(95 \% \mathrm{Cl})$ & $P$-value \\
\hline Age & $0.98(0.95-1.01)$ & 0.16 & & \\
\hline \multicolumn{5}{|l|}{ Stage } \\
\hline Early $(I+I I)$ & 1 & & & \\
\hline Advance (III+IV) & $3.21(1.58-5.19)$ & $<0.001$ & & \\
\hline \multicolumn{5}{|l|}{ Primary treatment } \\
\hline NACT & 1 & & & \\
\hline Surgery & $0.66(0.16-2.69)$ & 0.535 & & \\
\hline \multicolumn{5}{|l|}{ Surgical outcome } \\
\hline Optimal surgery & 1 & & 1 & \\
\hline Sub-optimal surgery & $4.54(1.01-3.51)$ & $<0.001$ & $2.68(1.48-4.87)$ & 0.002 \\
\hline \multicolumn{5}{|l|}{ Ascites cytology } \\
\hline Negative & 1 & & 1 & \\
\hline Positive & $3.79(2.21-6.49)$ & $<0.001$ & $2.80(1.58-4.98)$ & 0.002 \\
\hline \multicolumn{5}{|l|}{ LVSI } \\
\hline Negative & 1 & & 1 & \\
\hline Positive & $2.57(1.44-4.61)$ & 0.004 & $2.14(1.18-3.86)$ & 0.04 \\
\hline \multicolumn{5}{|l|}{ CA $125(\mathrm{IU} / \mathrm{mL})$} \\
\hline$\leq 35$ & 1 & & 1 & \\
\hline$>35$ & $1.88(1.01-3.50)$ & 0.034 & $1.56(0.83-2.94)$ & 0.149 \\
\hline \multicolumn{5}{|l|}{ Lymph node involvement } \\
\hline Negative & 1 & & & \\
\hline Positive & $3.30(1.68-6.47)$ & 0.001 & & \\
\hline
\end{tabular}

PFS, progression-free survival; HR, hazard ratio; Cl, confidence interval; NACT, neoadjuvant chemotherapy; LVSI, lymphovascular space invasion; CA 125, cancer antigen 125. 


\section{Obstetrics \& Gynecology Science}

Wikanda Hemman, et al. Recurrent clear cell ovarian carcinoma

come, ascites cytology, LVSI, preoperative level of CA 125, and lymph node involvement were found to have significantly poor PFS. Therefore, FIGO stage, surgical outcome, ascites cytology, LVSI, preoperative level of CA 125, and lymph node involvement were entered into the multivariate PFS analysis. The Cox multivariate analysis showed that residual tumor from surgical outcome, LVSI, and ascites cytology were independent prognostic factors for PFS. The significant variables were residual tumor ( $>1 \mathrm{~cm}$ vs. $<1 \mathrm{~cm}$ or no residual tumor) (HR, 2.68; 95\% Cl, 1.48-4.87; $P=0.002)$, LVSI (positive vs. negative) (HR, 2.14; $95 \% \mathrm{Cl}, 1.18-3.86 ; P=0.04)$, and ascites cytology (positive vs. negative) (HR, 2.8; $95 \% \mathrm{Cl}, 1.58-4.98 ; P=0.002)$.

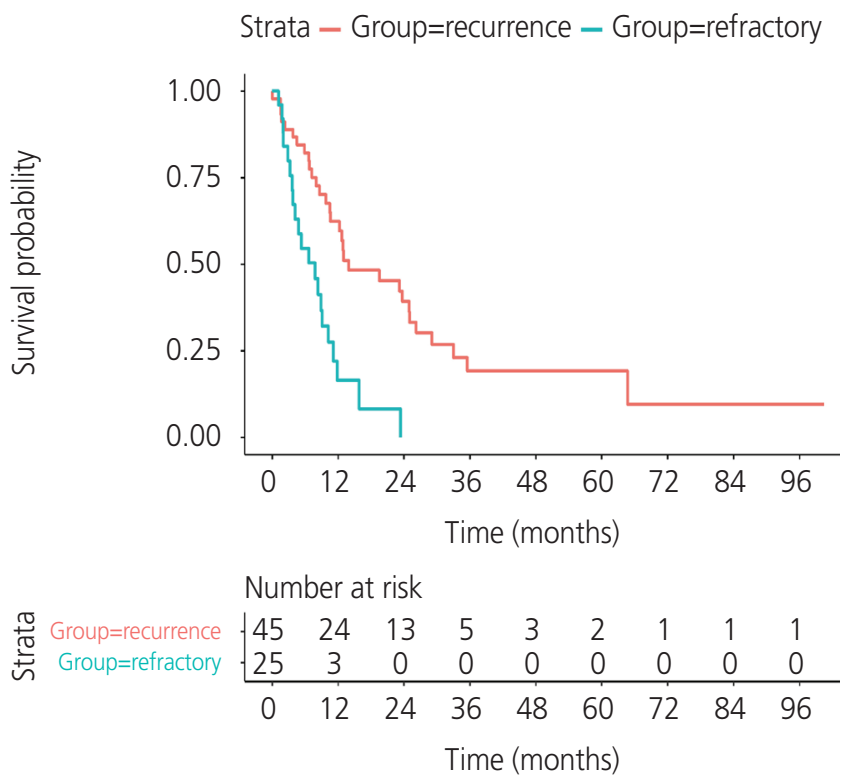

Fig. 3. Kaplan-Meier analysis of post-recurrence survival according to group.
The post-recurrence survival period in the recurrence group was 13.96 months $(95 \% \mathrm{Cl}, 10.61-26.2)$, and this was 7.8 months $(95 \% \mathrm{Cl}, 4.14-11.1)$ in the refractory group (Fig. 3). Most patients in the recurrence group $(29 / 45,64.4 \%)$ had multiple-site recurrence and 13/45 (28.9\%) had single-site recurrence (all 13 patients had recurrent tumors in the pelvis). Another three out of $45(6.7 \%)$ patients had nodal recurrence. The first patient had a single nodal recurrence in the right pelvic region. The second had four nodes above the left renal vein, and the last one had multiple nodal recurrences: seven nodes at both groins and pelvic and para-aortic lymph nodes (Supplementary Table 1). Multiple-site recurrence had a poorer prognosis than single-site recurrence and nodal recurrence (Supplementary Table 2).

Five patients had a prolonged post-recurrence survival of more than 36 months (Table 3). One patient had no evidence of disease, three patients were living with the disease, and one patient died from the disease 56.9 months after recurrence. The age range of the patients was $48-59$ years. They were initially diagnosed with FIGO stage II and underwent primary cytoreductive surgery followed by chemotherapy. The time of recurrence was 11-67 months. The pattern of recurrence in these patients was either single-site or nodal site recurrence. The treatment in these cases after recurrence was mainly chemotherapy. One patient was treated with tumor debulking surgery followed by chemotherapy, and the post-recurrence survival in this case was 105.1 months. Since these patients were classified as having platinum-sensitive recurrent ovarian cancer, all received reinduction chemotherapy with paclitaxel and carboplatin.

Table 3. Descriptive analysis of five patients with prolonged post-recurrence survival $>36$ months

\begin{tabular}{|c|c|c|c|c|c|c|c|c|}
\hline No. & $\begin{array}{l}\text { Age } \\
(y r)\end{array}$ & Stage & Primary treatment & $\begin{array}{c}\text { Time to recurrence } \\
\text { (months) }\end{array}$ & $\begin{array}{l}\text { Site of } \\
\text { recurrence }\end{array}$ & $\begin{array}{l}\text { Treatment for } \\
\text { recurrence }\end{array}$ & $\begin{array}{l}\text { Post-recurrence } \\
\text { survival (months) }\end{array}$ & $\begin{array}{c}\text { Disease } \\
\text { status }\end{array}$ \\
\hline 1 & 59 & $\|$ & $\begin{array}{l}\text { Cytoreductive surgery } \\
+ \text { CMT }\end{array}$ & 30.8 & $\begin{array}{l}\text { Single-site } \\
\text { pelvis }\end{array}$ & $\begin{array}{l}\text { Debulking surgery } \\
+ \text { CMT }\end{array}$ & 105.1 & NED \\
\hline 2 & 54 & $\|$ & $\begin{array}{l}\text { Cytoreductive surgery } \\
+ \text { CMT }\end{array}$ & 67.5 & $\begin{array}{l}\text { Single-site } \\
\text { pelvis }\end{array}$ & CMT & 56.9 & $\begin{array}{c}\text { Died from } \\
\text { disease }\end{array}$ \\
\hline 3 & 48 & $\|$ & $\begin{array}{l}\text { Cytoreductive surgery } \\
+ \text { CMT }\end{array}$ & 42.1 & $\begin{array}{l}\text { Single-site } \\
\text { pelvis }\end{array}$ & CMT & 39.4 & AWD \\
\hline 4 & 49 & $\|$ & $\begin{array}{l}\text { Cytoreductive surgery } \\
+ \text { CMT }\end{array}$ & 32.6 & $\begin{array}{l}\text { Pelvic lymph } \\
\text { node }\end{array}$ & CMT & 49.0 & AWD \\
\hline 5 & 55 & $\|$ & $\begin{array}{l}\text { Cytoreductive surgery } \\
+ \text { CMT }\end{array}$ & 11.5 & $\begin{array}{l}\text { Single-site } \\
\text { pelvis }\end{array}$ & CMT & 42.9 & AWD \\
\hline
\end{tabular}

CMT, chemotherapy; NED, no evidence of disease; AWD, alive with disease. 


\title{
Obstetrics \& Gynecology Science
}

\author{
Vol. 65, No. 2, 2022
}

\section{Discussion}

The incidence recurrence rate of CCC was $33.6 \%$, which was consistent with previous studies that reported rates of $26.9-30.3 \%$ [9-11]. The incidence of recurrence was $29.1 \%$ in early stage disease and $44.7 \%$ in advanced stage disease. These results were similar to those of a study by Hogen et al. [9] that reported recurrence rates of $26 \%$ in early stage disease. However, the recurrence rate in advanced stage disease was $67 \%$ [9], which is much higher than that reported in this study. Even though the percentage of patients that achieved an optimal surgery was relatively equivalent, this may have occurred because this study did not include patients with stage IV disease. Hreshchyshyn et al. [12] reported a recurrence rate of only $6 \%$ in stage I epithelial ovarian carcinoma after surgery and treatment with chemotherapy. In contrast, Sugiyama et al. [13] found that stage IC CCC had a higher rate $(37 \%)$ and shorter time of recurrence compared with serous adenocarcinoma.

The patients had a mean age at the time of diagnosis of 51 years. This was consistent with the results of a previous study in which the median age in patients with CCC was 4951 years old, which was significantly younger than that of patients with serous carcinoma of the ovary ( 55 vs. 64 years) [14-16]. The preoperative level of CA 125 was less than 35 $\mathrm{IU} / \mathrm{mL}$ (normal) in $23 \%$ of all patients in this study. A previous study also reported a normal CA 125 level in 19.4-39.1\% of patients with CCC $[17,18]$. Currently, the European Society for Medical Oncology and European Society of Gynaecologial Oncology consensus conference recommendations on ovarian cancer indicate that CA 125 is not a reliable marker in epithelial ovarian carcinoma types other than high-grade serous carcinoma [7]. Cases of suspected or diagnosed CCC with a negative level of CA 125 should be further investigated using alternative serum markers to improve early diagnosis and prognosis, as well as monitoring after treatment. Most CCC patients $(71.4 \%)$ presented with early stage disease, which is consistent with a previous study that reported early stage disease in $66.4-79 \%$ of patients $[3,9,19]$. In contrast, most patients (83.2\%) with serous carcinoma presented with advanced stage disease [3].

The median PFS in this study was 12.8 months $(95 \% \mathrm{Cl}$, 9.66-18.9) in the recurrence group. Most patients (77.7\%, 35/45) experienced recurrence within the first 2 years after the primary treatment. A previous study reported a median
PFS of 14.5-15.5 months [11,20]. This study found that early stage disease had a median PFS that was greater than that for advanced stage disease. In this study, the median PFS durations for stages I, II, and III were 17.5, 17.7, and 9.8 months. This study included patients with optimal and suboptimal surgical outcomes, while the study by Kajiyama et al. [11] included only CCC patients with complete resection outcomes; therefore, the PFS durations the aforementioned study might be different and longer than in this study.

Data on predictive factors for recurrent disease in CCC remain scarce. Most data on predictive factors for recurrence of epithelial ovarian carcinoma resulted from serous ovarian carcinoma. Lee et al. [6] reported that early stage (stage I), endometriosis, and optimal debulking were favorable prognostic factors for PFS. A previous retrospective study provided evidence that residual tumor status is an independent prognostic factor for patients with CCC [21]. Additionally, a retrospective study showed that LVSI was associated with a decreased PFS in stage I CCC, and they concluded that patients with stage I CCC showing LVSI may benefit from receiving postoperative chemotherapy [22]. Similarly, in this study, residual tumor from surgical outcome, LVSI, and positive ascites cytology indicated a worse prognosis for PFS. Unfortunately, CCC had a lower response rate to platinumbased chemotherapy (11.1\%) than serous adenocarcinoma (72.5\%) [13]. Maximal cytoreductive surgery should be attempted to delay recurrence and prolong survival in patients with CCC. Currently, the recommendation for adjuvant chemotherapy in CCC is still based on data from epithelial ovarian cancer trials, which are composed of a small number of CCC cases. They suggested that adjuvant chemotherapy was based mainly on the FIGO stage. However, this study showed that LVSI and positive ascites cytology indicated a worse prognosis for PFS. Therefore, further investigations on the values of other clinicopathological factors should be considered in personalized adjuvant therapy.

We found that multiple-site recurrence was the most common pattern of recurrence in CCC (64.4\%), and diffuse peritoneal involvement was the most common. This is consistent with a previous study that reported that $62 \%$ of patients had multiple-site recurrence [9]. Post-recurrence survival in this study was 13.96 months. Previous studies reported median post-recurrence survivals of 14.0-16.5 months $[11,19,23]$. Platinum sensitivity and primary stage were reported as independent prognostic factors for recurrent or persistent CCC, 


\section{Obstetrics \& Gynecology Science}

Wikanda Hemman, et al. Recurrent clear cell ovarian carcinoma

whereas chemotherapy regimens (paclitaxel plus carboplatin versus irinotecan plus cisplatin) did not demonstrate a significant difference [23]. Our investigations revealed that single-site and nodal site recurrences indicated a favorable prognosis for post-recurrence survival. It has been reported that surgical resection combined with systemic chemotherapy might improve the oncological outcome in patients with single-site recurrent CCC $[9,20]$. Kondo et al. [23] reported survival rates of tumor reduction surgery during recurrence. The median post-progression survival in the tumor reduction surgery group was significantly longer than in the non-tumor reduction surgery group (26.5 NA vs. 12.9 months) (HR, 0.23; $95 \% \mathrm{Cl}, 0.09-0.63 ; P=0.002)$ [23]. In agreement with this study, a patient who underwent debulking surgery followed by systemic chemotherapy had significantly longer postrecurrence survival than patients who received only systemic chemotherapy. The role of debulking surgery in single-site or nodal site recurrent CCC should be further evaluated to achieve promising oncological outcomes.

The limitations of this study are its retrospective study design and incomplete data. None of the patients in this study received bevacizumab as adjuvant therapy. Hence, the value of anti-angiogenic agents could not be evaluated. Nonetheless, this research was a single-institute study that discussed homogeneous management and had a sufficient follow-up period. The analysis provided useful information for counselling patients and their relatives.

Prospective studies should be attempted to provide more complete and accurate data. A prospective clinical trial on new molecular targeted therapies could result in better treatment options for patients with CCC.

In summary, the recurrence rate was $33.6 \%$ in patients with CCC. Sub-optimal surgery, LVSI, and positive ascites cytology indicated a worse prognosis for PFS. Optimal cytoreductive surgery is an important part of primary treatment to improve survival in patients with CCC. The treatment of recurrent disease should be individualized for patients, and optimal treatment should be offered to improve oncological outcomes.

\section{Conflicts of interest}

The authors have no conflict of interest.

\section{Ethical approval}

The study was approved by the Research Ethics Committee of the Faculty of Medicine, Prince of Songkla University (approval number 63-167-12-4).

\section{Patient consent}

Informed consent was waived due to the retrospective and anonymous nature of the study and participants.

\section{Funding information}

This study was supported by the Faculty of Medicine of the Prince of Songkla University.

\section{Acknowledgments}

We are grateful to Miss. Jirawan Jayuphan for helping with the statistical analysis.

\section{Supplementary material}

Supplementary Tables 1, 2 associated with this article can be found online at https://doi.org/10.5468/ogs.21313.

\section{References}

1. Sung $H$, Ferlay J, Siegel RL, Laversanne M, Soerjomataram I, Jemal A, et al. Global cancer statistics 2020: GLOBOCAN estimates of incidence and mortality worldwide for 36 cancers in 185 countries. CA Cancer J Clin 2021;71:209-49.

2. Scully RE, Young RH, Clement PB. Tumors of the ovary, maldeveloped gonads, fallopian tube, and broad ligament. In: Atlas of Tumor Pathology. 3rd ed. Washington DC: Armed Forces institute of Pathology; 1998. p.1-168.

3. Ku FC, Wu RC, Yang LY, Tang YH, Chang WY, Yang JE, et al. Clear cell carcinomas of the ovary have poorer outcomes compared with serous carcinomas: results from 


\section{Obstetrics \& Gynecology Science}

Vol. 65, No. 2, 2022

a single-center Taiwanese study. J Formos Med Assoc 2018;117:117-25.

4. Ha HI, Chang HK, Park SJ, Lim J, Won YJ, Lim MC. The incidence and survival of cervical, ovarian, and endometrial cancer in Korea, 1999-2017: Korea Central Cancer Registry. Obstet Gynecol Sci 2021;64:444-53.

5. lida Y, Okamoto A, Hollis RL, Gourley C, Herrington CS. Clear cell carcinoma of the ovary: a clinical and molecular perspective. Int J Gynecol Cancer 2021;31:605-16.

6. Lee YY, Kim TJ, Kim MJ, Kim HJ, Song T, Kim MK, et al. Prognosis of ovarian clear cell carcinoma compared to other histological subtypes: a meta-analysis. Gynecol Oncol 2011:122:541-7.

7. Colombo N, Sessa C, Du Bois A, Ledermann J, McCluggage WG, McNeish I, et al. ESMO-ESGO consensus conference recommendations on ovarian cancer: pathology and molecular biology, early and advanced stages, borderline tumours and recurrent disease. Ann Oncol 2019;30:672-705.

8. Armstrong DK, Alvarez RD, Bakkum-Gamez JN, Barroilhet L, Behbakht K, Berchuck A, et al. Ovarian cancer, version 2.2020, NCCN clinical practice guidelines in oncology. J Natl Compr Canc Netw 2021;19:191-226.

9. Hogen L, Vicus D, Ferguson SE, Gien LT, Nofech-Mozes S, Lennox GK, et al. Patterns of recurrence and impact on survival in patients with clear cell ovarian carcinoma. Int J Gynecol Cancer 2019;29:1164-9.

10. Kajiyama H, Mizuno M, Shibata K, Umezu T, Suzuki S, Yamamoto $E$, et al. A recurrence-predicting prognostic factor for patients with ovarian clear-cell adenocarcinoma at reproductive age. Int J Clin Oncol 2014;19:921-7.

11. Kajiyama H, Suzuki S, Yoshihara M, Nishino K, Yoshikawa N, Utsumi F, et al. The possible existence of occult metastasis in patients with ovarian clear-cell carcinoma who underwent complete resection without any residual tumours. Oncotarget 2018;9:6298-307.

12. Hreshchyshyn MM, Park RC, Blessing JA, Norris HJ, Levy $D$, Lagasse LD, et al. The role of adjuvant therapy in stage I ovarian cancer. Am J Obstet Gynecol 1980;15:139-45.

13. Sugiyama T, Kamura T, Kigawa J, Terakawa N, Kikuchi $Y$, Kita T, et al. Clinical characteristics of clear cell carcinoma of the ovary: a distinct histologic type with poor prognosis and resistance to platinum-based chemother- apy. Cancer 2000;88:2584-9.

14. Tang H, Liu Y, Wang X, Guan L, Chen W, Jiang H, et al. Clear cell carcinoma of the ovary: clinicopathologic features and outcomes in a Chinese cohort. Medicine (Baltimore) 2018;97:e10881.

15. Zhu C, Zhu J, Qian L, Liu H, Shen Z, Wu D, et al. Clinical characteristics and prognosis of ovarian clear cell carcinoma: a 10-year retrospective study. BMC Cancer 2021;21:322.

16. Chan JK, Teoh D, Hu JM, Shin JY, Osann K, Kapp DS. Do clear cell ovarian carcinomas have poorer prognosis compared to other epithelial cell types? A study of 1411 clear cell ovarian cancers. Gynecol Oncol 2008;109:370-6.

17. Kudoh K, Kikuchi Y, Kita T, Tode T, Takano M, Hirata J, et al. Preoperative determination of several serum tumor markers in patients with primary epithelial ovarian carcinoma. Gynecol Obstet Invest 1999;47:52-7.

18. Liu H, Xu Y, Ji J, Dong R, Qiu H, Dai X. Prognosis of ovarian clear cell cancer compared with other epithelial cancer types: a population-based analysis. Oncol Lett 2020;19:1947-57.

19. Sugiyama T, Okamoto $A$, Enomoto T, Hamano T, Aotani $E$, Terao $Y$, et al. Randomized phase III trial of irinotecan plus cisplatin compared with paclitaxel plus carboplatin as first-line chemotherapy for ovarian clear cell carcinoma: JGOG3017/GCIG trial. J Clin Oncol 2016;34:2881-7.

20. Huang HJ, Yang LY, Tung HJ, Ku FC, Wu RC, Tang YH, et al. Management and clinical outcomes of patients with recurrent/progressive ovarian clear cell carcinoma. J Formos Med Assoc 2020;119:793-804.

21. Takano M, Kikuchi Y, Yaegashi N, Kuzuya K, Ueki M, Tsuda $\mathrm{H}$, et al. Clear cell carcinoma of the ovary: a retrospective multicentre experience of 254 patients with complete surgical staging. Br J Cancer 2006;94:1369-74.

22. Matsuo K, Yoshino K, Hasegawa K, Murakami R, Ikeda Y, Adachi $S$, et al. Survival outcome of stage I ovarian clear cell carcinoma with lympho-vascular space invasion. Gynecol Oncol. 2015;136:198-204.

23. Kondo E, Tabata T, Suzuki N, Aoki D, Yahata H, Kotera Y, et al. The post-progression survival of patients with recurrent or persistent ovarian clear cell carcinoma: results from a randomized phase III study in JGOG3017/GCIG. J Gynecol Oncol 2020;31:e94. 